\title{
Capitalismo dependente e questão regional no século XXI: o caso do Centro-Oeste brasileiro
}

Pietro Caldeirini Aruto

Secretaria de Estado do Desenvolvimento Econômico Sustentável de Santa Catarina

Recebido: 24/05/2018 Versão revisada (entregue): 28/04/2019 Aprovado: 03/05/2019

\begin{abstract}
Resumo
O objetivo do artigo é relacionar os determinantes internacionais e nacionais do desenvolvimento capitalista dependente brasileiro com a questão regional, destacando o caso do Centro-Oeste. Metodologicamente, parte-se da teoria marxista da dependência para analisar a inserção da economia brasileira no sistema internacional e a superexploração da força de trabalho. Complementarmente, utilizam-se dados secundários para averiguar as mudanças na estrutura econômica e ocupacional no Brasil e no Centro-Oeste, os quais evidenciam a importância de criação rápida e elevada de um exército industrial de reserva, a extensão da jornada de trabalho e o rendimento setorial dos trabalhadores comparativamente ao Brasil. A análise teórica e empírica aponta que essa extroversão do capital sobre o território teve como base uma nova e específica forma de reprodução da força de trabalho no Centro-Oeste.
\end{abstract}

Palavras-chave | capitalismo dependente; Centro-Oeste; economia política; questão regional; superexploração da força de trabalho.

Código JEL | F54 J21 R58

Dependent capitalism and regional question in the 21st century: the case of the Brazilian Central-West

\begin{abstract}
The main purpose of the paper is to relate the Brazilian regional question to the determinants of the capitalist dependent development, highlighting Central-West region. Methodologically, the research is characterized by an investigative and empirical analysis, based on Marxist dependency theory and secondary official data organization. The research preliminarily indicates that the expressive occupations growth in Brazilian Central West is marked by adverse conditions on labor power reproduction, such as greater participation in occupations, in which the worked hours exceed 45 hours a week and high immigration rate resulting in an industrial reserve army. This evidence suggests that changes in regional labor power benefit capital expansion in Central West and result in a specific spatial production in urban and rural areas.
\end{abstract}

Keywords | Central-West; dependent capitalism; political economy; regional question; overexploitation of workforce. 
JEL-Code | F54 J21 R58

\section{Capitalismo dependiente y cuestión regional en el siglo XXI: el caso del Centro-Oeste brasileño}

\section{Resumen}

El objetivo del artículo es relacionar los determinantes internacionales y nacionales del desarrollo capitalista dependiente brasileño y la cuestión regional, destacando el caso del Centro-Oeste. Metodológicamente, se parte de la teoría marxista de la dependencia para analizar la inserción de la economía brasileña en el sistema internacional y la superexplotación de la fuerza de trabajo. Complementariamente, se utilizan datos secundarios para averiguar los cambios en la estructura económica y laboral en Brasil y Centro-Oeste, los cuales evidencian la importancia de la creación rápida y elevada de un ejército industrial de reserva, la extensión de la jornada de trabajo y el rendimiento sectorial de los trabajadores en comparación con Brasil. El análisis teórico y empírico muestra que la valorización del capital tuvo como base una nueva y específica forma de reproducción de la fuerza de trabajo en el Centro-Oeste.

Palabras-clave | capitalismo dependiente; Centro-Oeste; economía política; cuestión regional; superexplotación de la fuerza de trabajo.

Código JEL | F54 J21 R58

\section{Introdução}

De modo geral, duas grandes correntes de pensamento homogeneízam as interpretações econômicas sobre o (sub)desenvolvimento regional brasileiro, com variadas ramificações e interconexões entre elas. A primeira delas é uma derivação do individualismo e dedutivismo metodológico do pensamento neoclássico e sua ênfase na circulação mercantil. A segunda corrente se origina do pensamento histórico-estruturalista e desenvolvimentista latino-americano e constitui um contraponto ao pensamento dedutivo e a-histórico da economia convencional neoclássica. Ainda que contrastantes entre si, foge a essas duas correntes uma concepção totalizante do desenvolvimento do modo de produção capitalista, tanto na sua dimensão nacional, quanto regional. Ambas não partem da relação social mais fundamental: a que ocorre entre os homens e a natureza numa sociedade de classes. Em outras palavras, não encaram a exploração capitalista e a relação dos trabalhadores com o produto do seu trabalho como a categoria de análise mais concreta e totalizante.

Com base nessa questão metodológica, o objetivo do artigo é relacionar os determinantes internacionais e nacionais do desenvolvimento capitalista 
dependente brasileiro com a questão regional na contemporaneidade, destacando o caso do Centro-Oeste brasileiro. Mais especificamente, procura-se problematizar, teórica e empiricamente, como as mudanças na força de trabalho e na estrutura econômica na região centro-oeste brasileiro condicionam e resultam na produção social do espaço que reproduz a dependência em uma escala regional.

Diante do desenvolvimento ainda insuficiente dessa abordagem, a investigação possui um caráter eminentemente exploratório e multidisciplinar. Por um lado, recuperam-se criticamente as principais categorias da produção social do espaço no Brasil. Por outro, parte-se da teoria da dependência para analisar de forma totalizante a inserção da economia brasileira no sistema internacional e como que ela implica numa superexploração da força de trabalho. Complementarmente a essa abordagem teórica, utilizam-se dados secundários para averiguar as mudanças na estrutura econômica (Contas Regionais/IBGE) e ocupacional (PNAD/IBGE) no Brasil e no Centro-Oeste.

O artigo está estruturado em mais duas seções, além das considerações finais. A primeira seção procura expor os determinantes estruturais da inserção da economia brasileira no sistema econômico internacional, a configuração de política econômica subjacente a essa inserção, bem como, as mudanças na estrutura econômica e ocupacional. A seção posterior parte dessa determinação internacional e nacional para analisar a questão regional brasileira, ao destacar a estrutura ocupacional dos trabalhadores do Centro-Oeste Brasileiro a partir dos $\operatorname{anos} 2000$.

\section{Padrão de reprodução do capital no Brasil contemporâneo}

As transformações socioeconômicas que perpassam as regiões de uma nação estão atreladas, em última instância, à necessidade de expansão do capital pelo território, nas distintas formações socioespaciais. O espraiamento e a reprodução das relações capitalistas no território, por sua vez, são condicionados pelo padrão de reprodução do capital, ou seja, pelas características históricas e espaciais presentes nas metamorfoses do capital no processo de valorização e pela capacidade do Estado em instrumentalizar esse movimento (OSORIO, 2012a, p. 40-41). Historicamente, essas condições de valorização do capital se transformaram com o esgotamento do processo de industrialização brasileira (1930-1980) e a inserção subordinada da economia nacional à globalização econômica a partir de um projeto neoliberal de desenvolvimento (CANO, 2017).

A "globalização econômica", enquanto o resultado das novas condições técnicas e econômicas desenvolvidas nos países do centro a partir da década de 1970, tornou necessária uma nova forma de organização do mercado e do processo produtivo mundial. Nesse sentido, os países do centro possuem duas vantagens que ampliam 
o nível de dependência dos países periféricos. A inovação técnica, ao ter como base atividades de pesquisa e desenvolvimento, torna-se inacessível aos países da periferia, a não ser quando se configuram como receptores de novas plantas industriais, o que leva à segunda vantagem. As nações desenvolvidas controlam a transferência das atividades produtivas pelo deslocamento de indústrias menos intensivas em conhecimento e pela dispersão das etapas produtivas dentre os países, o que dificulta a integração inter e intrassetorial nos periféricos. Dessa forma, a divisão internacional do trabalho se mostra de maneira mais complexa e heterogênea, onde os países periféricos mantêm a produção primária e/ou de bens industriais pautada em uma crescente dependência tecnológica junto aos países do centro do sistema capitalista (MARINI, 1996).

Trata-se, assim, de transformações nas formações socioespaciais dependentes dentro da nova dinâmica do modo de produção capitalista, onde a própria nação e sua relação com as regiões subnacionais são alteradas. Nesse sentido, os esquemas e as formas de produção e realização do produto nacional passam por uma nova configuração, sintetizados como um padrão de reprodução do capital exportador de especialização produtiva (PRCEEP) (OSORIO, 2012aа 2012b).

A condição fundamental do novo padrão é seu viés exportador, ou seja, os setores mais dinâmicos do novo padrão estão atrelados ao mercado externo. Dessa forma, o PRCEEP tende a repousar sobre a produção agrícola, mineral e alguns bens industriais intensivos em mão de obra e favorecidos por tratados comerciais, principalmente nas áreas de montagem, maquiladoras e serviços. Concomitantemente ao aumento do volume de exportações há a elevação também das importações, o que implica em uma integração e subordinação cada vez maior com o centro capitalista, o que altera a integração produtiva nacional comparativamente ao padrão anterior.

Diante dessas tendências, observa-se uma especialização produtiva e a presença de enclaves econômicos: reduzidas atividades econômicas com maior conteúdo tecnológico, com pouca relação à estrutura produtiva e elevado grau de coeficiente de importação. O resultado é o fim da industrialização como um projeto de maior autonomia (relativa) econômica. Em poucos países, como Brasil e México, alguns segmentos industriais se mantêm, mas integrados ao projeto exportador e dentro de grandes cadeias produtivas globais comandadas por empresas transnacionais.

As tendências do PRCEEP verificam-se nos países periféricos de maneira diversa. Ainda assim, no caso do Brasil, conforme pode ser visto no Gráfico 1, ao se contrastar o período do padrão de reprodução industrializante (no gráfico, 19551980) com o PRCEEP pós 1980, percebem-se as tendências antes assinaladas: 1) a extroversão da produção para o mercado externo, com um aumento da participação das exportações no total do PIB (no auge do ciclo de exportação da década de 2000, a participação chegou a mais de $15 \%$ do PIB); 2) a participação da indústria é reduzida significativamente, principalmente com a adoção do Plano 
Real em 1994 e a sobrevalorização cambial que se seguiu; 3) redução da taxa de investimento (FBCF/PIB) e do crescimento econômico como um todo. 


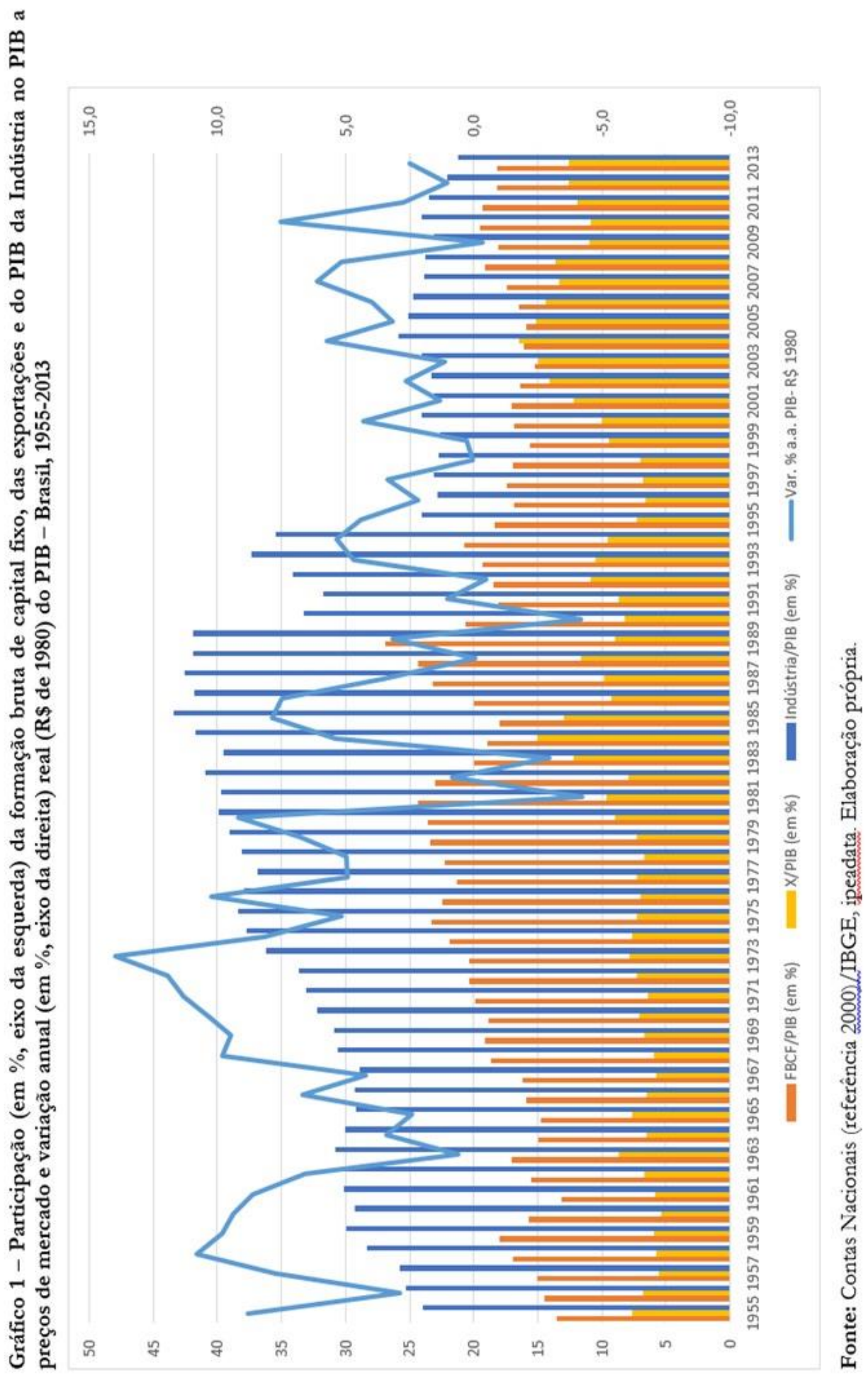

48 | Revista Brasileira de Desenvolvimento Regional, Blumenau, 7 (1), P. 43-66, 2019 
Dessa forma, as condições específicas de valorização do capital na formação socioespacial dependente brasileira significaram uma especialização regressiva da estrutura produtiva e um maior comando do capital estrangeiro sobre a dinâmica nacional (CANO, 2017; CARCANHOLO, 2015). Essa maior posição dependente tem como base uma orientação específica da política econômica a qual fornece as condições macroeconômicas de valorização do capital internamente, bem como sua extroversão ao exterior. No caso do Brasil, a configuração básica de política econômica que se seguiu ficou conhecida como "tripé macroeconômico": taxa de juros utilizada para combater o nível de preços interno e atrair capital externo, política fiscal de superávit primário para conter o nível de gastos do governo e conferir solvência e credibilidade aos títulos públicos e política cambial flutuante para garantir a compensação internacional do Balanço de Pagamentos, ainda que o Banco Central intervenha dentro de determinados parâmetros. Dessa forma, o tripé macroeconômico conferiu os parâmetros básicos para maior dependência externa e hegemonia do capital financeiro sobre o orçamento público e o capital produtivo, reforçando, assim as tendências econômicas e produtivas associadas ao PRCEEP.

Além de uma configuração específica de política econômica, os governos federais na década de 1990 promoveram uma série de reformas "neoliberalizantes" as quais procuraram alterar e enfraquecer o papel do Estado na coordenação da acumulação ampliada de capital e permitir uma maior apropriação do setor financeiro no bojo da globalização econômica. Entre essas reformas, destacam-se: a abertura comercial (redução de tarifas de importação e adesão à Organização Mundial do Comércio); reforma financeira (desregulamentação sobre o movimento do capital estrangeiro, ampliando a conversibilidade da conta capital do balanço de pagamentos e a desnacionalização da parcela das empresas do setor financeiro nacional, com base no acordo de Basiléia) e a reforma trabalhista, que permitiu flexibilizar e precarizar as relações de trabalho (entre outros, a ampliação dos fatores incidentes na demissão por justa causa, eliminação da indexação legal e automática do salário mínimo, criação do banco de horas, redução da jornada de trabalho com redução do salário e ampliação das terceirizações) (CANO, 2017).

Por trás da dependência externa, de uma política econômica contracionista e da mitigação do papel do Estado como indutor do desenvolvimento capitalista dependente, encontra-se uma deterioração das condições de vida dos trabalhadores brasileiros a partir da década de 1990. Dentre as transformações presenciadas no mundo do trabalho, destacam-se: a queda dos salários reais; aumento e intensificação das jornadas; ampliação do desemprego e precarização das relações; redução do salário indireto por meio de privatização e corte de direitos e serviços públicos; reorganização do processo de trabalho com a introdução de inovações tecnológicas e gerenciais que aumentaram a produtividade e reduziram o número de trabalhadores produtivos (CANO, 2008). 
Essas medidas foram mobilizadas para aumentar a taxa de exploração e rotação de várias frações do capital.

Nos anos 2000, o contexto internacional e as políticas novo-desenvolvimentistas resultaram em modificações importantes no mercado de trabalho nacional. A partir de 2003, o Brasil experimentou um crescimento econômico acima do verificado na década anterior, propiciado não só pelas exportações, mas, principalmente, pelo consumo interno e pela formação bruta de capital fixo, categorias vinculadas às políticas estatais implementadas a partir de então (LÚCIO; DUCA, 2016). Dessa forma, foi possível um aumento da renda per capita e no nível de ocupações sem precedentes, sobretudo em postos formais de trabalho, os quais, somados às políticas de combate à pobreza e ao aumento do investimento público, permitiram uma redução na desigualdade de rendimentos e conquistas sociais (BARBOSA; PEREIRA, 2010).

Contudo, essas condições são revertidas a partir de final de 2014, por um lado, pelo recrudescimento da crise externa e, por outro, pelas medidas de ajuste fiscal implementadas pós-eleição presidencial. Dessa forma, o crescimento da economia diminui, uma vez que os fatores ligados à demanda interna perdem dinamicidade e a produção industrial apresenta uma desaceleração. A partir de então, observa-se a prevalência das tendências históricas do subdesenvolvimento no mercado de trabalho: aumento do desemprego, queda do nível de ocupações e aumento da informalidade.

A trajetória cíclica da economia brasileira nos anos 2000 revela a estrutura do subdesenvolvimento e da dependência interna e externamente no Brasil. Quanto à dependência externa, Prates e De Rezende (2015) apontam que a tendência histórica de déficit nas contas correntes do Balanço de Pagamentos foi mitigada apenas durante o 2003-2008, com o aumento expressivo dos saldos comerciais. A partir de então, a economia brasileira apresentou déficits crescentes nas transações correntes, compensados pela entrada de capital estrangeiro (investimento em carteira e direto) e/ou utilização das reservas internacionais, instrumentos esses que não resolvem a questão estrutural de transferência de recursos ao exterior.

A contribuição decisiva e radical da teoria da dependência foi demonstrar que a contraparte da dependência externa é a superexploração da força de trabalho (SFT). A superexploração ocorre quando a força do trabalho é remunerada abaixo do seu valor, mediante baixos salários associados a um aumento da jornada de trabalho $\mathrm{e} / \mathrm{ou}$ da sua intensidade. Isso resulta em uma transferência de fundos de consumo dos trabalhadores para o capital, no sentido de recompor sua taxa de lucro sem passar um aumento na produtividade do trabalho (MARINI, 2005). A configuração dos mecanismos de superexploração varia conforme os padrões de reprodução do capital e eles se expressam historicamente e espacialmente especificamente, como pretende-se problematizar a seguir. De toda forma, esses mecanismos de exploração estão ligados à existência de uma elevada desigualdade 
no mercado de trabalho, com a presença de um expressivo exército industrial de reserva e reduzidas ocupações em segmentos com elevada produtividade.

Uma questão polêmica diz respeito às condições, ao nível e aos mecanismos de SFT no auge do governo novo-desenvolvimentista do PT. Por um lado, o aumento dos salários médio real e mínimo, a queda do desemprego, o aumento da formalização dos postos de trabalho e a diminuição da jornada de trabalho deram mostras de uma contenção relativa da superexploração. Por outro lado, Mathias Luce (2013) considera distintos mecanismos e níveis na SFT no período, ao constatar: a) que aumento real do salário mínimo no governo do PT não recompôs o valor do salário mínimo necessário do DIEESE; b) com essa lacuna, a reprodução da força de trabalho está comprometida, inclusive ao somar o valor do salário mínimo dos homens e das mulheres; c) a permanência de um elevado contingente (40\% em média) de trabalhadores que possuem jornada acima das 44 horas semanais; d) a evidência de aumento da intensidade da jornada de trabalho em alguns segmentos industriais, como a automobilística, sucroalcooleiro e telemarketing; e) outra evidência de aumento de intensidade da jornada a partir da elevação dos acidentes de trabalho entre 2001 e 2008 (o que deve ser relativizado, dado o aumento de ocupações formais e a fiscalização); f) o aumento do endividamento das famílias, o que leva que parte expressiva dos salários seja apropriada pelo capital portador de juros.

A despeito da polêmica, o ponto aqui defendido é que a melhora das condições de vida das famílias trabalhadoras na primeira década do século XXI, sob o governo do PT, não significou uma superação da dependência e da SFT. Mais do que isso, a contenção relativa da SFT foi possível diante da excepcionalidade da conjuntura econômica internacional a qual permitiu que a rentabilidade de diversas frações do capital internamente não dependesse tanto da remuneração da força de trabalho abaixo do valor ${ }^{1}$. Contudo, a contenção relativa da SFT e as políticas novodesenvolvimentistas se mostraram incompatíveis com o desenrolar da crise de 2008, como sugere a trajetória do mercado de trabalho pós-2011, sobretudo com a recessão 2015-2016: aumento do desemprego e da pobreza, estagnação do salário médio real, aumento da desigualdade de renda, entre outros.

Mais estritamente ao objetivo desse texto, defende-se aqui que tanto a contenção relativa da SFT, e sua reversão posterior, quanto a evolução da economia brasileira no período como um todo estão intimamente relacionadas com a produção social do espaço em várias escalas, inclusive a regional. Em outras palavras, o atual padrão de reprodução do capital significa um uso intenso e extensivo do território e da força de trabalho nacionais em um processo contraditório de homogeneização e diferenciação espacial. Como será visto, a região Centro-Oeste

\footnotetext{
${ }^{1}$ Além das políticas econômicas e sociais mais voltadas ao mercado interno e distribuição de renda.
} 
constitui um caso particular da determinação nacional sobre uma porção específica do território nacional.

\section{A região Centro-Oeste: a divisão regional do trabalho e estrutura ocupacional a partir da década 2000}

A subseção anterior procurou expor, sinteticamente, os principais determinantes da inserção da economia brasileira no sistema econômico internacional, a configuração da política econômica subjacente a essa inserção, bem como as mudanças na estrutura econômica. Nesse sentido, as novas relações estabelecidas com o sistema econômico internacional a partir de 1980 têm como base tanto uma transformação no mundo do trabalho como também uma nova forma de produção social do espaço e, assim, da divisão regional do trabalho no Brasil. Como enfatiza Adrían Sotelo Valencía (2016, p. 140), a heterogeneidade do mercado de trabalho e a precarização dos vínculos laborais na América Latina a partir de 1990 constituem uma totalidade que se reflete diferencialmente pelos países e regiões a partir da estrutura econômica e social.

É partir desses pressupostos que se pode analisar sob várias escalas espaciais o Centro-Oeste brasileiro enquanto região brasileira que mais se transformou do ponto de vista espacial a partir da consolidação do PRCEEP (DE MACEDO, 2010). Conforme periodização realizada por Cano (2008), o Centro-Oeste brasileiro se insere no processo de desconcentração produtiva nos anos de 1970, no auge das políticas de planejamento regional e de industrialização, para além de São Paulo. Contudo, a partir da década de 1980, mas, sobretudo na seguinte, com o esgotamento da industrialização e emergência de políticas neoliberais, esse processo de desconcentração se manteve, ainda que de forma "espúria". Isso porque o ganho de participação das regiões periféricas na estrutura produtiva se deve mais a um "efeito estatístico" do que a maior dinâmica regional (ou seja, a periferia também diminui o seu ritmo de crescimento, porém, a uma intensidade menor que a da região polo industrial).

A desconcentração produtiva no território brasileiro avança, principalmente nas áreas de expansão da fronteira agromineral como a região Norte, Centro-Oeste, Rio de Janeiro (no caso, extração de petróleo) e Espírito Santo. Por sua vez, o Nordeste recupera a posição perdida nas últimas duas décadas e a região Sul e Minas Gerais, que desenvolveram um importante parque industrial durante o processo de industrialização, reduziram a sua participação, mas com um crescimento positivo. Dessa forma, o grande perdedor é São Paulo, precisamente a região que em termos capitalistas mais avançara no processo de industrialização (CANO, 2008). 
Conjunturalmente, a partir dos anos 2000, observa-se a intensificação dessa tendência, por um lado, pelo crescimento das exportações de commodities que se beneficiam do aumento internacional de preços (Efeito-China) e, por outro, por uma política econômica que mantém a desindustrialização. Na Tabela 01, constata-se a tendência de queda da participação de São Paulo no Produto Interno Bruto (PIB) nacional durante todo período, com uma participação de 34,9\% em 2002 e, em 2015, 32,4\%. A macrorregião Sul mantém o mesmo patamar de 16\%, com alguma oscilação. Nesse sentido, foram as regiões periféricas que mais ganharam participação entre 2002 e 2015, sobretudo, a região Norte (4,7\% e $5,4 \%)$, Nordeste $(13,1 \%$ e $14,2 \%$ ) e Centro-Oeste (8,6\% e 9,7\%).

Tabela 1 - Participação (em \%) no Produto Interno Bruto do Brasil Grandes Regiões e São Paulo 2002-2015

\begin{tabular}{l|r|r|r|r|r|r|r|r|r|r|r|r|r|r}
\hline & 2002 & 2003 & 2004 & 2005 & 2006 & 2007 & 2008 & 2009 & 2010 & 2011 & 2012 & 2013 & 2014 & 2015 \\
\hline Norte & 4,7 & 4,7 & 5,0 & 4,9 & 5,0 & 5,0 & 5,0 & 5,0 & 5,3 & 5,5 & 5,4 & 5,5 & 5,3 & 5,4 \\
\hline Nordeste & 13,1 & 12,8 & 12,9 & 13,0 & 13,2 & 13,0 & 13,1 & 13,6 & 13,5 & 13,3 & 13,6 & 13,6 & 13,9 & 14,2 \\
\hline Sudeste & 57,4 & 56,5 & 56,5 & 57,5 & 57,7 & 57,4 & 57,0 & 56,3 & 56,1 & 56,1 & 55,9 & 55,3 & 54,9 & 54,0 \\
\hline São Paulo & 34,9 & 34,4 & 33,4 & 34,2 & 34,2 & 34,4 & 33,5 & 33,8 & 33,3 & 32,8 & 32,4 & 32,2 & 32,2 & 32,4 \\
\hline Sul & 16,2 & 17,1 & 16,8 & 15,9 & 15,6 & 16,1 & 16,0 & 15,9 & 16,0 & 15,9 & 15,9 & 16,5 & 16,4 & 16,8 \\
\hline Centro-Oeste & 8,6 & 8,9 & 8,9 & 8,6 & 8,4 & 8,6 & 8,9 & 9,3 & 9,1 & 9,1 & 9,2 & 9,1 & 9,4 & 9,7 \\
\hline
\end{tabular}

Fonte: Contas Regionais/IBGE; elaboração própria.

Ainda que sejam as macrorregiões periféricas do Norte, Nordeste e do CentroOeste as que mais aumentaram a participação PIB no período, os determinantes associados a elas foram distintos, principalmente quando se analisa as atividades produtivas. Nesse sentido, a macrorregião Centro-Oeste expressa por excelência a desconcentração produtiva baseada em uma especialização e intensificação da agroindustrial e agricultura/pecuária do cerrado. Fundamental para esse processo foi a (re)orientação das políticas estatais, sobretudo, as de planejamento regional. Em um primeiro momento, durante o período de industrialização, com a presença do Estado na coordenação da acumulação de capital no território brasileiro - pela ampliação dos gastos públicos e pelos investimentos estatais - a economia do Centro-Oeste passou por uma relativa diversificação econômica e produtiva. $\mathrm{O}$ objetivo era manter a região como provedora de alimentos e matérias-primas para os demais centros industriais, cujas atividades foram concentradas em grandes empresas nacionais e estrangeiras, sem romper com o latifúndio. Esse movimento, ao longo do tempo, teve como base a utilização crescente de recursos públicos, os 
deslocamentos populacionais nos projetos de colonização e a utilização dos fundos territoriais (DE MACEDO; RAMOS, 2015).

A partir dos anos de 1990, conforme estratégia neoliberal mencionada, é possível observar tanto uma redução dos fundos públicos destinados ao desenvolvimento regional (3\% sobre o imposto de renda e produtos industrializados) como também a orientação deles não para mitigar as desigualdades regionais, mas, sim, para beneficiar as atividades associadas ao padrão de reprodução do capital, como no Centro-Oeste. Essa orientação específica de planejamento regional a partir dos anos 2000 pode ser visualizada quando se observa que 50\% dos fundos para o desenvolvimento regional são destinados para regiões de alta renda. Ou, ainda, quando o financiamento do BNDES prioritariamente se destina a grandes empresas nacionais e estrangeiras concentradas nas regiões Sul e Sudeste (CARLEIAL, 2014). Por trás dessa configuração de política pública está a questão da submissão dos interesses do Estado Nacional à lógica do capital e do capitalismo dependente.

Em síntese, o crescimento da região Centro-Oeste acima da média brasileira, assentado na produção agroindustrial, deve ser visto a partir dos determinantes postos pelo padrão de reprodução do capital, pela conformação de uma política econômica e por uma orientação específica das políticas públicas. Esses condicionantes transformaram completamente o território da região Centro-Oeste nas últimas décadas, tornando-o uma "verdadeira plataforma de exportação de produtos agropecuários e agroindustriais (para dentro e para fora do país), pelo aproveitamento de sua condição de área de fronteira, o que deu continuidade à itinerância da agricultura brasileira, agora em base tecnificada e com forte introjeção tecnológica" (DE MACEDO, 2010, p. 192). Isso pode ser visto a partir da Tabela 2, que trata da participação do valor adicionado bruto (VAB) dos setores na região Centro-Oeste em relação ao VAB do Brasil. Percebe-se que o crescimento da região entre 2002 e 2015 tem como base os setores agropecuário, industrial, construção, utilidade pública e comércio. Esses setores da região aumentaram sua participação no VAB nacional tanto no período de aceleração do crescimento (até 2010) quanto no período de desaceleração e início da recessão em 2015, o que evidencia o caráter estrutural dos determinantes nacionais sobre a região. 
Tabela 2 - Participação (em \%) do VAB do Centro-Oeste no VAB do Brasil segundo atividades econômicas, 2002-2015

\begin{tabular}{|c|c|c|c|c|c|c|c|c|c|c|c|c|c|c|}
\hline $\begin{array}{c}\text { Atividades } \\
\text { Econômicas }\end{array}$ & 2002 & 2003 & 2004 & 2005 & 2006 & 2007 & 2008 & 2009 & 2010 & 2011 & 2012 & 2013 & 2014 & 2015 \\
\hline $\begin{array}{l}\text { Total das } \\
\text { Atividades }\end{array}$ & 8,9 & 9,1 & 9,2 & 8,9 & 8,6 & 8,8 & 9,2 & 9,5 & 9,3 & 9,3 & 9,4 & 9,3 & 9,6 & 9,9 \\
\hline Agropecuária & 15,9 & 17,6 & 18,9 & $\mid 16,9$ & 11,5 & 14,0 & 16,7 & 17,0 & 16,4 & 18,1 & 20,8 & 19,3 & 19,1 & 19,2 \\
\hline $\begin{array}{l}\text { Indústrias } \\
\text { extrativas }\end{array}$ & 1,8 & 1,7 & 1,8 & 1,2 & 0,9 & 1,9 & 1,2 & 2,1 & 1,4 & 1,3 & 1,3 & 1,1 & 1,2 & 1,7 \\
\hline $\begin{array}{l}\text { Indústrias de } \\
\text { Transformação }\end{array}$ & 4,0 & 3,9 & 4,0 & 4,1 & 4,2 & 4,1 & 4,5 & 4,9 & 5,1 & 5,1 & 5,6 & 5,9 & 5,7 & 5,8 \\
\hline $\begin{array}{l}\text { Eletricidade e gás, } \\
\text { água, esgoto, } \\
\text { atividades de } \\
\text { gestão de resíduos } \\
\text { e descontaminação }\end{array}$ & 8,7 & 10,2 & 10,7 & 9,7 & 9,2 & 9,8 & 10,4 & 10,1 & 9,6 & 9,7 & 10,9 & 11,7 & 12,1 & 12,3 \\
\hline Construção & 8,2 & 7,8 & 9,0 & 9,1 & 8,2 & 8,4 & 8,4 & 8,7 & 9,2 & 9,2 & 8,7 & 8,8 & 9,6 & 9,4 \\
\hline $\begin{array}{l}\text { Comércio e } \\
\text { reparação de } \\
\text { veículos } \\
\text { automotores e } \\
\text { motocicletas }\end{array}$ & 7,4 & 9,2 & 8,6 & 8,5 & 8,1 & 8,5 & 9,6 & 9,5 & 8,8 & 8,9 & 9,1 & 8,7 & 9,4 & 9,1 \\
\hline $\begin{array}{l}\text { Transporte, } \\
\text { armazenagem e } \\
\text { correio }\end{array}$ & 7,1 & 5,6 & 5,5 & 5,3 & 6,1 & 6,3 & 6,2 & 6,8 & 6,9 & 7,3 & 6,9 & 6,6 & 6,5 & 7,5 \\
\hline $\begin{array}{l}\text { Alojamento e } \\
\text { alimentação }\end{array}$ & 8,0 & 6,9 & 8,3 & 8,8 & 7,1 & 8,4 & 9,7 & 8,1 & 8,0 & 7,7 & 8,1 & 7,7 & 8,3 & 8,5 \\
\hline $\begin{array}{l}\text { Informação e } \\
\text { comunicação }\end{array}$ & 6,4 & 6,8 & 6,6 & 6,1 & 6,9 & 6,3 & 6,6 & 6,9 & 6,6 & 6,0 & 6,0 & 5,9 & 6,3 & 6,6 \\
\hline $\begin{array}{l}\text { Atividades } \\
\text { financeiras, de } \\
\text { seguros e serviços } \\
\text { relacionados }\end{array}$ & 10,0 & 9,2 & 10,0 & 9,7 & 9,8 & 9,0 & 9,8 & 9,3 & 9,8 & 9,9 & 9,7 & 9,8 & 10,5 & 10,6 \\
\hline $\begin{array}{l}\text { Atividades } \\
\text { Imobiliárias }\end{array}$ & 7,6 & 7,8 & 8,1 & 8,2 & 8,2 & 8,7 & 8,4 & 8,4 & 8,6 & 8,8 & 8,6 & 8,4 & 8,6 & 8,8 \\
\hline $\begin{array}{l}\text { Atividades } \\
\text { profissionais, } \\
\text { científicas e } \\
\text { técnicas, } \\
\text { administrativas e } \\
\text { serviços } \\
\text { complementares }\end{array}$ & 6,8 & 7,1 & 6,9 & 6,5 & 6,9 & 6,7 & 6,8 & 6,6 & 6,9 & 6,6 & 6,9 & 6,7 & 7,3 & 7,0 \\
\hline $\begin{array}{l}\text { Administração, } \\
\text { defesa, educação e } \\
\text { saúde públicas e } \\
\text { seguridade social }\end{array}$ & 15,2 & 15,2 & 16,0 & 15,7 & 16,0 & 15,6 & 15,8 & 15,9 & 15,9 & 15,9 & 15,3 & 15,1 & 15,2 & 15,6 \\
\hline $\begin{array}{l}\text { Educação e saúde } \\
\text { privadas }\end{array}$ & 6,1 & 6,7 & 6,4 & 6,6 & 7,3 & 7,3 & 7,3 & 7,3 & 7,2 & 7,2 & 7,4 & 6,3 & 7,3 & 7,8 \\
\hline $\begin{array}{l}\text { Outras atividades } \\
\text { de serviços }\end{array}$ & 8,3 & 8,8 & 8,8 & 8,9 & 9,0 & 9,0 & 9,1 & 9,0 & 9,3 & 9,3 & 9,6 & 9,5 & 9,4 & 9,5 \\
\hline
\end{tabular}

Fonte: Contas Regionais/IBGE; elaboração própria.

Como discutido na seção anterior, a hipótese defendida é que essa extroversão do capital sobre o território teve como base uma nova forma de reprodução da força 
de trabalho e do espaço na região Centro-Oeste. Nesse sentido, procura-se, a seguir, destacar indícios que apontam especificamente à superexploração das ocupações na região Centro-Oeste com base nos dados demográficos e populacionais da PNAD/IBGE, elaborados por Aruto e Gomes Junior (2017). Os dados a seguir, ainda que de forma preliminar, procuram problematizar as mudanças no mercado de trabalho da região Centro-Oeste, associando-as com as transformações na estrutura produtiva e na produção social do território.

Nesse sentido, a Tabela 3 enfatiza o crescimento da população ocupada ao longo do ciclo econômico: ocupados cresceram acima da PEA durante a expansão (2002-2011), com o comportamento inverso para o período seguinte (2011-2015). No caso da região Centro-Oeste, a tendência foi a mesma, mas chama a atenção a magnitude dessa evolução, com uma incorporação elevada de força de trabalho no auge e uma queda não tão brusca na ocupação no período de crise.

A incorporação de trabalhadores a esse nível só foi possível mediante a presença de força de trabalho de outras regiões. Observa-se que, durante o ciclo ascendente de crescimento (2002-2011), a população não-natural do município e do Estado de residência cresceu (1,6\% a.a.) em um patamar próximo ao da população residente como um todo $(1,8 \%)$. A maior participação de mão de obra migrante no CentroOeste é resultado, por um lado, dos projetos de colonização e deslocamento populacionais de décadas anteriores, mas, por outro, da necessidade contemporânea de incorporar crescentemente força de trabalho nas regiões de fronteira de acumulação de capital, garantindo que a taxa salarial não ameace o nível da taxa de lucro. Categoricamente, os fatos apontam a criação e necessidade de um exército industrial de reserva para garantir uma oferta de força de trabalho elástica à produção. 
Tabela 3 - Variação ao ano (em \%) da população residente, em idade ativa, economicamente ativa, ocupada e residentes não naturais do município e da UF - Brasil e Centro-Oeste, 2002, 2011 e 2015

\begin{tabular}{|c|c|c|c|c|}
\hline \multicolumn{2}{|r|}{ Variáveis e Níveis Geográficos } & $\begin{array}{l}\text { Variação } \\
\text { média \% } \\
\text { a.a. } \\
2002 / 2011\end{array}$ & $\begin{array}{c}\text { Variação } \\
\text { média \% a.a. } \\
20011 / 2015\end{array}$ & $\begin{array}{c}\text { Variação } \\
\text { média \% a.a. } \\
\text { 2002/2015 }\end{array}$ \\
\hline \multirow{5}{*}{ BR } & População Residente & 1,4 & 0,9 & 1,2 \\
\hline & PIA & 1,9 & 1,2 & 1,7 \\
\hline & PEA & 1,6 & 1,0 & 1,4 \\
\hline & Ocupados & 1,9 & 0,2 & 1,4 \\
\hline & Residentes Não naturais no município e na UF & 1,1 & 0,2 & 0,8 \\
\hline \multirow{5}{*}{$\mathrm{CO}$} & População Residente & 1,8 & 1,5 & 1,7 \\
\hline & PIA & 2,4 & 1,8 & 2,2 \\
\hline & PEA & 2,3 & 1,6 & 2,1 \\
\hline & Ocupados & 2,6 & 1,0 & 2,1 \\
\hline & Residentes Não naturais no município e na UF & 1,6 & 0,3 & 1,2 \\
\hline
\end{tabular}

Fonte: PNAD/IBGE, elaboração própria.

Como destacam Amaral e Carcanholo (2012, p. 100-101), a disponibilidade de amplos contingentes força de trabalho é um dos pressupostos para aumentar a sua exploração. Nesse aspecto, os dados da Tabela 4 corroboram tendencialmente esse pressuposto ao se destacar a participação dos ocupados segundo atividades econômicas e jornadas de trabalho acima das 45 horas semanais. Observa-se que o maior nível de ocupação no período (Tabela 3) deu-se em detrimento das atividades agrícolas e dos serviços domésticos, ainda que esses conservassem uma elevada participação em 2014 (12\% e 7\%, respectivamente). Por sua vez, a indústria de transformação manteve o patamar de participação durante todo o período, ou seja, cresceu no mesmo ritmo elevado das ocupações em geral. As demais atividades que mais ganharam participação foram construção, alimentação/alojamento, administração pública e transporte/armazenagem. Em geral, são atividades cuja dinâmica está ligada ao espaço urbano e condicionadas pelas atividades produtivas da indústria de transformação e agrícola. 
Tabela 4 - Proporção (em \%) dos ocupados por grupos de horas habitualmente trabalhadas por semana na ocupação principal* segundo grupos de atividade econômica (em \%)** - Centro-Oeste e Brasil, 2002, 2011 e 2014

\begin{tabular}{|c|c|c|c|c|c|c|}
\hline \multirow{2}{*}{ Atividades Econômicas } & \multicolumn{3}{|c|}{ Brasil } & \multicolumn{3}{|c|}{ Centro-Oeste } \\
\hline & 2002 & 2011 & 2014 & 2002 & 2011 & 2014 \\
\hline \multicolumn{7}{|l|}{ Todas as atividades } \\
\hline (A) & 100 & 100 & 100 & 100 & 100 & 100 \\
\hline (B) & 37,4 & 28,5 & 24,4 & 43,4 & 30,6 & 26,1 \\
\hline \multicolumn{7}{|l|}{ Agrícola } \\
\hline (A) & 20,7 & 15,7 & 14,5 & 17,7 & 11,9 & 11,9 \\
\hline (B) & 33,3 & 27,5 & 21,7 & 51,8 & 45,4 & 37,0 \\
\hline \multicolumn{7}{|l|}{ Indústria de Transformação } \\
\hline (A) & 13,5 & 12,6 & 12,3 & 9,9 & 9,7 & 9,9 \\
\hline (B) & 37,1 & 27,5 & 23,5 & 48,8 & 34,6 & 27,1 \\
\hline \multicolumn{7}{|l|}{ Construção } \\
\hline (A) & 7,1 & 8,4 & 9,2 & 7,7 & 9,4 & 10,3 \\
\hline (B) & 48,0 & 33,9 & 25,9 & 56,4 & 38,4 & 27,8 \\
\hline \multicolumn{7}{|l|}{ Comércio e reparação } \\
\hline (A) & 17,2 & 17,8 & 18,2 & 18,9 & 18,9 & 19,0 \\
\hline (B) & 49,0 & 37,7 & 35,1 & 53,4 & 38,1 & 33,3 \\
\hline \multicolumn{7}{|l|}{ Alojamento e alimentação } \\
\hline (A) & 3,7 & 4,9 & 4,7 & 3,9 & 5,0 & 5,3 \\
\hline (B) & 55,5 & 44,5 & 40,8 & 58,5 & 41,7 & 42,5 \\
\hline \multicolumn{7}{|c|}{ Transporte, armazenagem e comunicação } \\
\hline (A) & 4,7 & 5,5 & 5,5 & 4,6 & 5,1 & 5,1 \\
\hline (B) & 54,3 & 42,3 & 37,9 & 55,3 & 45,7 & 40,0 \\
\hline \multicolumn{7}{|l|}{ Administração pública } \\
\hline (A) & 4,9 & 5,4 & 5,2 & 6,8 & 7,9 & 7,6 \\
\hline (B) & 20,1 & 12,5 & 10,4 & 18,2 & 11,4 & 10,5 \\
\hline \multicolumn{7}{|l|}{ Educação, saúde e serviços sociais } \\
\hline (A) & 8,9 & 9,2 & 10,3 & 8,8 & 9,5 & 9,9 \\
\hline (B) & 14,8 & 11,9 & 10,2 & 16,6 & 10,4 & 9,8 \\
\hline \multicolumn{7}{|l|}{ Serviços domésticos } \\
\hline (A) & 7,7 & 7,1 & 6,5 & 9,2 & 7,9 & 7,0 \\
\hline (B) & 40,0 & 25,2 & 18,8 & 36,6 & 21,8 & 17,6 \\
\hline \multicolumn{7}{|c|}{ Outros serviços coletivos, sociais e pessoais } \\
\hline (A) & 4,0 & 3,8 & 4,2 & 4,6 & 4,1 & 4,3 \\
\hline (B) & 32,7 & 27,1 & 24,9 & 35,3 & 25,8 & 23,2 \\
\hline \multicolumn{7}{|l|}{ Outras atividades } \\
\hline (A) & 6,6 & 8,7 & 8,7 & 7,1 & 9,4 & 8,8 \\
\hline (B) & 30,8 & 21,4 & 18,2 & 29,4 & 17,5 & 14,6 \\
\hline
\end{tabular}


* (A) - Ocupados em relação ao total dos ocupados na unidade geográfica (em \%). ** (B) - Ocupados acima de 45 horas (\% em relação aos ocupados no setor de atividade).

Fonte: PNAD/IBGE; elaboração Própria

A Tabela 4 fornece ainda informações sobre a proporção de ocupados que trabalhavam acima de 45 horas por semana (linha B) nos respectivos setores econômicos. Ainda que declinante, o comportamento setorial das ocupações deuse com a preservação da participação de ocupados que trabalhavam acima de 45 horas semanais no trabalho principal: $26 \%$ para os trabalhadores em média do CO em 2014, mas no auge do ciclo de crescimento (2011), essa participação era de $30 \%$. Para aquelas atividades econômicas que mais aumentaram a participação, essa proporção foi substancialmente mais elevada (exceção da administração pública). Além disso, estruturalmente, os trabalhadores do Centro-Oeste apresentam uma jornada média de horas por semana acima do patamar médio brasileiro em praticamente todos os setores, sobretudo aqueles mais expressivos do PRCEEP

Por fim, procura-se problematizar a renda dos trabalhadores da região. Concretamente, a determinação do valor da força de trabalho e do seu preço é um processo complexo que passa pelo trabalho socialmente necessário dos meios de subsistência, a quantidade deles, por um conteúdo histórico e moral e luta de classes, além das especificidades setoriais (ARAUJO, 2016). Contudo, a determinação do salário deve levar em conta também a questão espacial, principalmente em um país territorialmente extenso e marcado por profundas desigualdades regionais.

Para ilustrar o último argumento, destaca-se a seguir (Tabela 5) a renda média real por hora trabalhada e a jornada de trabalho média dos trabalhadores da construção civil, segmento que concentra contingente expressivo de trabalhadores do Brasil e Centro-Oeste nas últimas décadas (como visto na Tabela 4). Esse corte é fundamental para, minimamente, poder se relacionar o preço da força de trabalho em um setor na média nacional e em casos (regiões) específicos. 
Tabela 5 - Rendimento (em R\$) médio real (INPC de fevereiro de 2018) por hora trabalhada e jornada semanal (horas) médias na ocupação principal dos empregados da produção da construção civil segundo formalização** Brasil e Centro-Oeste*, 2002 e 2015

\begin{tabular}{c|l|c|c|c|c}
\hline \multirow{2}{*}{ Variáveis } & \multicolumn{2}{c|}{ BR } & \multicolumn{2}{c}{ CO (-DF) } \\
\cline { 3 - 6 } & \multicolumn{1}{c|}{} & $\mathbf{2 0 0 2}$ & $\mathbf{2 0 1 5}$ & $\mathbf{2 0 0 2}$ & $\mathbf{2 0 1 5}$ \\
\hline \multirow{2}{*}{$\begin{array}{c}\text { Com carteira de } \\
\text { trabalho }\end{array}$} & Horas trabalhadas por semana & 46,1 & 42,5 & 48,3 & 43,3 \\
\cline { 2 - 6 } & $\mathrm{R} \$ /$ hora & 6,5 & 9,8 & 5,5 & 10,5 \\
\hline \multirow{2}{*}{$\begin{array}{c}\text { Sem carteira de } \\
\text { trabalho }\end{array}$} & Horas trabalhadas por semana & 44,5 & 39,5 & 46,0 & 41,5 \\
\cline { 2 - 6 } & $\mathrm{R} \$ /$ hora & 4,2 & 7,1 & 4,2 & 8,2 \\
\hline
\end{tabular}

*exclusive DF

** somente aqueles ligados a atividades produtivas

Fonte: Microdados da PNAD/IBGE-elaboração própria.

Num primeiro momento, focando os trabalhadores com carteira, chama atenção do $\mathrm{CO}$ recebiam um rendimento por hora trabalhada menor daquele verificado no Brasil, $\mathrm{R} \$ 5,5 /$ hora e $\mathrm{R} \$ 6,5 /$ hora, respectivamente. Posteriormente, em 2015, a diferença passa a ser levemente positiva em favor dos trabalhadores do CO (R \$ 0,7 por hora). Esse fato, para além das políticas desenvolvimentistas ou da tendência de homogeneização dos rendimentos, deve ser visto a partir das condições de inserção dos trabalhadores no setor e das determinações nacionais e regionais: a) ainda que tenha diminuída, a jornada média dos trabalhadores do Centro-Oeste é aproximadamente duas horas a mais por semana do que os do Brasil, assim, esse aumento no nível salarial não necessariamente permite reproduzir normalmente o valor da força de trabalho, a depender da proporção desgaste/reposição da força de trabalho; b) associado à questão anterior, há fortes indícios que o aumento do salário na região Centro-Oeste se deu com aumento da exploração, basta lembrar que entre 2002 e 2015, segundo a tabela 2, o setor de construção aumentou em 1,2 p.p. sua participação no VAB brasileiro, ou seja, tudo indica que a produção de trabalho excedente proporcionalmente foi muito maior no Centro-Oeste e contou com um salário inicial abaixo do Brasil (o que deve ser conjugado com a análise da intensidade e produtividade no setor/região); c) o crescimento do salário médio na região Centro-Oeste no período final deve-se também à vigência de um menor exército industrial de reserva, em termos relativos, não por menos, assiste-se historicamente a correntes migratórias que garantem que o capital encontre trabalhadores em conformidade às necessidades do processo de valorização, como discutido a partir da Tabela 3.

Os dados apresentados procuraram delimitar, a partir da teoria social crítica latinoamericana, como a reprodução da dependência deve ser analisada em várias escalas espaciais e a partir da conjuntura econômica e política. No caso da região Centro-Oeste, na contemporaneidade, a dinâmica econômica baseada na produção 
agromineral contou com modificações na estrutura ocupacional, onde a incorporação da força de trabalho na região se fez com a preservação de importantes desigualdades laborais frente à média nacional, destacando o caso da duração da jornada de trabalho e da formação do exército industrial de reserva. Em outras palavras, apesar da melhora relativa dos indicadores socioeconômicos na primeira década do Século XXI, são fortes os indícios de que a diferença entre o valor da força de trabalho e sua remuneração foi fundamental para a valorização do capital, especificamente na região Centro-Oeste e de modo geral na formação socioespacial dependente brasileira.

As mudanças na força de trabalho na região consubstanciaram o uso intensivo e extensivo do território regional a partir dos determinantes do padrão de reprodução do capital. De fato, além da exploração da força de trabalho, o crescimento econômico da região Centro-Oeste esteve assentado na elevada produtividade do território nas atividades agropecuárias. Apenas para ilustrar o argumento, com base no estudo de Meade et al. (2016), o Brasil configura-se como um dos principais produtores e exportadores de soja em grande parte devido ao desempenho recente do Centro-Oeste: em 2010, o Brasil tinha o menor custo por barril de soja dentre os três principais produtores (juntamente com EUA e Argentina), US $\$ 7,47$, sendo que regionalmente no Mato Grosso o custo foi ainda menor, US\$6,60. Independente da origem dessa produtividade (localização, natural-orgânica ou inversão de capital), ela permite a formação de um lucro-extraordinário que, devido ao caráter monopolizável da propriedade fundiária, é apropriado como renda da terra pelo proprietário fundiário.

Infelizmente, foge do escopo desse texto aprofundar a relação entre renda terra e padrão de reprodução de capital no Brasil na atualidade. A sua menção nesse momento serve para explicitar o ponto aqui defendido: as mudanças na força de trabalho estão associadas a uma permanente transformação do território em diversas escalas espaciais, dentro da unidade da formação socioespacial dependente.

\section{Considerações Finais}

O objetivo desse artigo foi relacionar os determinantes internacionais e nacionais do desenvolvimento capitalista dependente brasileiro com a questão regional na contemporaneidade. Mais especificamente, a discussão foi dirigida para a região Centro-Oeste, enquanto porção do território que mais se transformou do ponto de vista produtivo nas últimas décadas. Na primeira seção, procurou-se analisar o atual padrão de reprodução do capital e se destacou o sentido exportador dessa produção, a hegemonia das grandes empresas transnacionais, bem como a política econômica subjacente a esses processos. Na segunda seção, discutiram-se os mecanismos de SFT problematizando-os a partir de formas espaciais, no caso, na 
região Centro-Oeste. Foi visto, em primeiro lugar, a importância de criação rápida e elevada de um exército industrial de reserva no Centro-Oeste. Em seguida, destacou-se setorialmente a extensão elevada da jornada de trabalho e o rendimento dos trabalhadores da construção civil, comparativamente à média brasileira. Conforme discutido, o crescimento econômico da região Centro-Oeste acima da média brasileira a partir dos anos $2000 \mathrm{em}$ grande parte se deve aos mecanismos de superexploração, ainda que ela tenha se arrefecido relativamente no período analisado (muito devido ao ciclo do preço das commodities e sua repercussão sobre as várias formas de rendimento do capital).

A perspectiva aqui defendida é de que a melhora dos indicadores sociais e laborais ao longo dos anos 2000 no Brasil e na região Centro-Oeste não significou a superação da superexploração. Pelo contrário, a disseminação das relações de produção capitalistas pelo território nacional teve como base a prevalência da remuneração da força de trabalho abaixo do seu valor, tendo em vista a desconcentração das atividades produtivas em direção às regiões periféricas e o aumento das ocupações nessas regiões. Esse movimento, por sua vez, se deu com a manutenção de um patamar elevado de desigualdade inter-regional, mesmo durante o auge do crescimento econômico, o qual se agravou, posteriormente, com a recessão e estagnação econômica pós 2015, como atualmente se observa (IBGE, 2018).

Por fim, o intuito desse texto foi analisar a economia dependente brasileira na atualidade destacando sua manifestação espacial na escala regional. Nesse sentido, o texto procurou contribuir com essa abordagem de uma dupla forma. Do ponto de vista teórico, enfatizou-se como a força de trabalho nacional se apresenta de forma particular e, por vezes, contraditória, nas regiões subnacionais o que exige, por excelência, uma análise totalizante dos fenômenos particulares. Do ponto de vista empírico, o texto procurou confrontar as análises e os argumentos com dados secundários relativos à estrutura econômica nacional e regional e à força de trabalho. Ainda que deva ser aprofundada, a abordagem aqui defendida permite avançar tanto na perspectiva da teoria marxista da dependência, ao desdobrar análises da dependência e da superexploração para outras escalas espaciais, como também na área de desenvolvimento regional, marcada em geral por investigações hipotético-dedutivas ou descritivas e empiricistas. O ponto fundamental é compreender a exploração da força de trabalho no Brasil em suas múltiplas determinações histórico-espaciais.

\section{Agradecimentos}

Gostaria de agradecer a Evaldo Gomes Jr. e Fernando Cezar de Macedo pela leitura e comentários, eximindo-os de qualquer erro que possa persistir no texto. 


\section{REFERÊNCIAS}

AMARAL, M.; CARCANHOLO, M. D. Superexploração da força de trabalho e transferência de valor: fundamentos da reprodução do capitalismo dependente. Padrão de reprodução do capital. São Paulo: Boitempo, p. 87-102, 2012.

ARAUJO, E. S. Sobre as Categorias Valor e Preço da Força de trabalho em Marx. Economias-Ensaios, Uberlândia, 30 (2), p. 185-205, jan./jun. 2016.

ARUTO, P. C.; GOMES JUNIOR, E. Padrão de reprodução do capital e produção social do espaço na região centro-oeste a partir da década de 2000. Anais ...XXII Encontro Nacional de Economia política. Campinas, p. 1-19, 2017. Disponível em: http://www.sep.org.br/downloads>. Acesso em: mai. 2018.

BARBOSA, N.; PEREIRA, S.J.A. A inflexão do governo Lula: política econômica, crescimento e distribuição de renda. In: SADER, E. GARCIA, M.A. (orgs). Brasil, entre o passado e o futuro. São Paulo: Boitempo, Perseu Abramo, p. $57-110,2010$.

CANO, W. Desconcentração Produtiva Regional do Brasil: 1970-2005. 1. ed. São Paulo: Unesp, 2008.

CANO, W. Brasil: construção e desconstrução do desenvolvimento Texto para discussão. Campinas: Instituto de Economia/Unicamp, n. 304, jun. 2017, 44 p.

CARCANHOLO, M. Neoliberalismo y dependencia contemporánea: la actual lucha de clases por la transformación social. In: VILLAGRA, L. (org). Neoliberalismo en América Latina: Crisis, tendencias y alternativas. Asunción: CLACSO, p. 263-282, 2015.

CARLEIAL, L. O desenvolvimento regional brasileiro ainda em questão. In: RANDOLPH, R. DIQUEIRA, H.; OLIVEIRA, A.(orgs) Planejamento, políticas e experiências de desenvolvimento regional: problemáticas e desafios. Rio de Janeiro: Letra Capital, p. 35-56, 2014.

MACEDO, F. C. de. Inserção Externa e Território: impactos do comércio exterior na dinâmica regional e urbana no Brasil (1989-2008). 2010. Tese (Livre Docência). Instituto de Economia, Universidade Estadual de Campinas, Campinas, 2010. 
MACEDO, F. C. de; RAMOS, P. A História de um Município Projetado (Sinop/MT): Qual é o seu Futuro? Revista Eletrônica Documento/Monumento, Mato Grosso, v. 19, p. 276-288, 2016.

IBGE (Instituto Brasileiro de Geografia e Estatística). PNAD Contínua: 10\% da população concentravam quase metade da massa de rendimentos do país em 2017. Agência IBGE Notícias, 11 de abril de 2018. Disponível em: https://agenciadenoticias.ibge.gov.br/agencia-sala-de-imprensa/2013-agencia-denoticias/releases/20843-pnad-continua-10-da-populacao-concentravam-quasemetade-da-massa-de-rendimentos-do-pais-em-2017. Acesso em: jun. 2018.

LUCE, M. S. A superexploração da força de trabalho no Brasil: evidências da história recente. ALMEIDA FILHO, N. Desenvolvimento e dependência. Brasília, IPEA, p. 145-166, 2013.

LÚCIO, C. e DUCA, F. Crise econômica e mercado de trabalho no Brasil. Carta Social e do Trabalho, Campinas: CESIT-IE/Unicamp, n. 33, p. 1-16, jan./jun. 2016.

LÚCIO, C. e DUCA, F. Transformação econômica, inserção externa e dinâmica territorial no Centro-Oeste brasileiro: o caso de Rio Verde. Revista Sociedade \& Natureza, Uberlândia, v. 25, n. 1, p. 35-50, 2013.

MARINI, R. Dialética da Dependência. In: TRASPADINI, R., STEDILE, J. P. (orgs). Ruy Mauro Marini: Vida e Obra. SP: Expressão Popular, 2005.

MARINI, R. Proceso y tendencias de la globalización capitalista. In: MARINI, R. e MILLÁN, M. (orgs). La teoría social latinoamericana, v. 4, p. 49-68, 1996.

MEADE, B. et al. Corn and Soybean Production Costs and Export Competitiveness in Argentina, Brazil, and the United States. Economic Information Bulletin. Economic Research Services/USDA n; 154. 2016, 46p.

OSORIO, Jaime. Padrão de reprodução do capital: uma proposta teórica. In FERREIRA, C. OSORIO; J. LUCE, M. (orgs). Padrão de reprodução do capital: contribuições da teoria marxista da dependência. São Paulo: Boitempo, p. 37-86, 2012.

OSORIO, Jaime. América Latina: o novo padrão exportador de especialização produtiva-estudo de cinco economias da região. In FERREIRA, C. OSORIO; J. LUCE, M. (orgs). Padrão de reprodução do capital: contribuições da teoria marxista da dependência. São Paulo: Boitempo, p. 103-133, 2012. 
PRATES, R. C.; DE REZENDE, A. A. Considerações a respeito do Balanço de Pagamentos: uma análise da evolução e dinâmica das contas brasileiras no período 2000-2014. Revista Paranaense de Desenvolvimento-RPD, Curitiba, v. 36, n. 128, p. 65-81, 2015.

SOTELO, A. Dependência, precariedade laboral e fratura social na América Latina com as reformas neoliberais. Argumentum. (Vitória), v. 8, n. 2, p. 140-152, mai./ago. 2016. 
Pietro Caldeirini Aruto

Endereço para correspondência:

Pietro Caldeirini Aruto - pietro.aruto@gmail.com

Mauro Ramos, 722, Centro

88.020-300 Florianópolis/SC, Brasil

66 | Revista Brasileira de Desenvolvimento Regional, Blumenau, 7 (1), P. 43-66, 2019 